Review

\title{
Rheumatic Diseases in the Elderly
}

Chiara Castellani ${ }^{1}$, Emanuele Molteni ${ }^{1}$, Serena Colafrancesco ${ }^{1}$, Fabrizio Conti ${ }^{1}$, Roberta Priori ${ }^{2}$, Rossana Scrivo ${ }^{1, *}$

1. Department of Clinical Internal, Anesthesiological and Cardiovascular Sciences, Rheumatology Unit, Sapienza University of Rome, Rome, Italy; E-Mails: chiara.castellani@uniroma1.it; emanuele.molteni@uniroma1.it;

serena.colafrancesco18@gmail.com;

fabrizio.conti@uniroma1.it; rossana.scrivo@uniroma1.it

2. Rheumatology Unit, Policlinico Umberto I, 00161 Rome, Italy and UniCamillus, Saint Camillus International University of Health Sciences, 00131 Rome, Italy; E-Mail: r.priori@policlinicoumberto1.it

* Correspondence: Rossana Scrivo; E-Mail: rossana.scrivo@uniroma1.it

Academic Editor: James S. Powers

Special Issue: Rheumatic Diseases in Older Adults

\section{OBM Geriatrics}

2020 , volume 4 , issue 4

doi:10.21926/obm.geriatr.2004139
Received: August 13, 2020

Accepted: October 26, 2020

Published: November 18, 2020

\begin{abstract}
Musculoskeletal conditions represent one-third to more than one-half of all noncommunicable disease multimorbidities in the elderly, worsening their disability because of pain and limited physical function, often concurring with their mental decline. Musculoskeletal conditions significantly contribute to frailty and global disability, second only to mental health conditions. Furthermore, premature mortality, generally due to an increased risk of developing cardiovascular disease, has been documented in several rheumatic diseases, including osteoarthritis, gout, vasculitis, etc., which largely affect older people. In the elderly, rheumatic diseases cover a spectrum of conditions affecting all age groups, especially those are seen more often in the aging population. This non-systematic review focuses on the elderly and may hopefully contribute to raising awareness of these issues beyond the rheumatology community. We believe that this constitutes a critical step
\end{abstract}

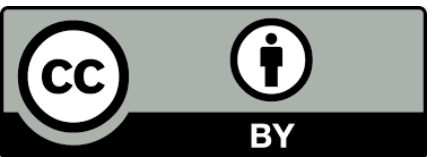

(C) 2020 by the author. This is an open access article distributed under the conditions of the Creative Commons by Attribution License, which permits unrestricted use, distribution, and reproduction in any medium or format, provided the original work is correctly cited. 
for prompt and proper diagnosis and referral of patients to ameliorate their overall longterm outcome.

\section{Keywords}

Geriatric rheumatic diseases; elderly rheumatic patients; musculoskeletal diseases; polymyalgia rheumatica; gout; septic arthritis

\section{Introduction}

According to the European League Against Rheumatism (EULAR) definition, "rheumatic diseases, also called musculoskeletal diseases, are characterized by pain and a consequent reduction in the range of motion and function in one or more areas of the musculoskeletal system; in some diseases, there are signs of inflammation: swelling, redness, and warmth in the affected areas. Rheumatic diseases can also affect internal organs" [1]. Most patients with chronic rheumatic diseases experience reduced workability and deteriorating quality of life because of pain and limited physical function, with a consequent adverse impact on their mental well-being [2].

Since the prevalence of many musculoskeletal conditions increases with age, these outcomes may even be more severe in older adults already weakened by limiting physical and mental capacities [2]. In 2001, the concept of physical frailty in the elderly was established, indicating the presence of five components: perceived exhaustion, weight loss, low levels of handgrip strength, gait speed, and physical activity [3]. This concept has subsequently been revisited. Therefore, physical frailty is now defined as a syndrome associated with aging that causes increased vulnerability to stressors due to deficiencies between various interrelated physiological systems, leading to a decline in homeostasis [4]. Furthermore, premature mortality, often due to an increased risk of developing cardiovascular disease, has been documented in several rheumatic diseases, including osteoarthritis (OA), gout, vasculitis, etc., that largely affect older people [5-7].

\section{Polymyalgia Rheumatica}

Polymyalgia rheumatica (PMR) is a common inflammatory disease observed in individuals at the age of 50 years or older [8].

In Italy, its prevalence is between $0.37 \%$ and $0.62 \%$, with an incidence of 2.3 cases $/ 1000$ population [9]. In a Japanese cohort, the prevalence of PMR was $0.22 \%$ in men and $0.36 \%$ in women [10]. The incidence in the Olmsted County (Minnesota) cohort was 69.8/100000 among women and 44.8/100000 among men [11].

An association between PMR and polymorphisms in the promoter region of the interleukin- 6 (IL-6) gene has been reported [12], while HLA-DRB1*04 class II alleles were mainly found in PMR associated with giant cell arteritis (GCA) [13]. Acting on a genetic predisposition, many environmental factors including infectious agents, may have a role in the onset of the disease. A peak of incidence of PMR has been observed in correspondence of epidemics of M. pneumoniae, C. pneumoniae, Parvovirus B19, adenovirus (AdV), and respiratory syncytial virus. This observation, together with the occurrence of PMR a few months apart in non-consanguineous and 
cohabiting subjects [14], suggests role of microbial agents. Another pathogenetic hypothesis derives from the observation that many patients rapidly respond to glucocorticoids (GCs), implying that disturbances of the hypothalamic-pituitary-gonadal axis may occur due to endocrinosenescence, an age-related decline of dehydroepiandrosterone (DHEA) or androstenedione (ASD) $[15,16]$.

The clinical presentation of PMR is characterized by sudden and severe pain and stiffness in the neck, shoulders, upper arms, and pelvic girdle, sometimes preceded by constitutional symptoms and elevation of inflammatory indexes [8]. Some clinical conditions associated with PMR may include GCA, subclinical vascular damage, and diverticular disease [17-19].

In 2012, a collaborative initiative of the EULAR and the American College of Rheumatology (ACR) prompted provisional criteria for the diagnosis of PMR [20]. These criteria, still needing further validation, apply to people aged 50 years or older with new-onset bilateral shoulder pain, abnormal C-reactive protein (CRP) levels and/or erythrocyte sedimentation rate (ESR). An algorithm then follows, where a score of at least 4 showed $65 \%$ sensitivity and $78 \%$ specificity for discriminating PMR from non-PMR patients. Ultrasonography (US) of shoulders and hips may be used to improve specificity. A score of 5 or greater should be achieved, with $66 \%$ sensitivity and 81\% specificity for classification of PMR compared with other disorders [20].

A formula to assess disease activity (PMR activity score) is proposed below

PMR activity score $=$ CRP $(\mathrm{mg} / \mathrm{dL})+$ VAS (visual analogue scale) patient's pain $(0-10)+$ VAS physician assessment + morning stiffness (minutes) x 0,1 + EUL (elevation of the upper limbs)

Where EUL indicates the ability to elevate upper limbs, to which a score from 0 (ability to raise the upper limbs beyond the upper girdle) to 3 (incapacity to raise the upper limbs beyond the upper girdle) is given. A final score lower than 7 displays a low disease activity, from 7 to 17 a moderate activity, and greater than 17 a high activity [21].

The diagnosis of PMR is based on clinical features and laboratory work-up, but the US can be helpful, according to the provisional 2012 criteria. Magnetic resonance imaging (MRI), computed tomography (CT), and positron emission tomography (PET) scans can also be used in situations where systemic vasculitis is suspected to be associated with PMR [22].

The treatment of PMR is based on GCs. In 2015, EULAR published the recommendations for the management of PMR, suggesting the use of the minimum effective GC dose, starting with 12.5-25 $\mathrm{mg}$ prednisone equivalent daily, with slow tapering to reach an oral dose of $10 \mathrm{mg} /$ day prednisone equivalent within 4-8 weeks. If relapse occurs, the dose should be increased to the pre-relapse dose and then decreased within 4-8 weeks to the dose at which the relapse occurred. In cases of contraindications to GCs, or resistant PMR, methotrexate (MTX) can be considered. In the management of PMR, it is very important to evaluate comorbidities and to assess the potential side effects of GCs [23].

Cardiovascular risk seems to be increased in patients with PMR, as demonstrated in a crosssectional study where the subclinical vascular damage was higher compared to patients with major cardiovascular risk factors [18]. Besides, the rate of vascular events was reported to be 36.1 per 1000 person-years in patients with PMR against 12.2 per 1000 person-years in patients without PMR [24]. 


\section{Remitting Seronegative Symmetrical Synovitis with Pitting Edema}

Remitting seronegative symmetrical synovitis with pitting edema (RS3PE) was first reported in 1985 by McCarty et al. [25]. A Japanese study recently reported a prevalence of $0.09 \%$ among patients of RS3PE in an outpatient clinic [10].

Infectious agents in a genetically predisposed host have been hypothesized as pathogenetic triggers [25].

This condition typically affects elderly people and is characterized by acute symmetrical synovitis of the extremities associated with pitting edema of the dorsum of both hands and feet, with limitation of motion of wrists and fingers. Rheumatoid factor (RF) is not present, and elevation of inflammatory indexes is often detected. Radiological erosions are not reported [25]. In an Italian study, patients with distal extremity swelling (unilateral or lower extremity involvement or both) and pitting edema were investigated with hand and foot MRI scans, which demonstrated that the extensor tenosynovitis of the hands and feet is the predominant lesion, with concomitant joint synovitis in some cases. Patients responded rapidly to GCs, as previously reported in a study [26]. RS3PE may present as an idiopathic disease, but in some cases, it is associated with other conditions, including PMR [27], spondyloarthropathies [28, 29], RA [30], systemic lupus erythematosus (SLE) [31]. Moreover, paraneoplastic RS3PE syndrome has been reported [32, 33].

\section{Giant Cell Arteritis}

GCA is a non-necrotizing granulomatous vasculitis that affects large and middle-sized arteries and occurs in elderly people, more frequently in women (M: F ratio 1:2), although it has rarely been reported to occur before the age of 50 years. It is the most common type of primary vasculitis in Western countries, with a prevalence of 304 and 81 per 100000/population in women and men, respectively [34]. The incidence of the disease peaks in the 70-79-year age group [35, 36]. As mentioned above, patients with PMR can show manifestations of GCA, while $40 \%$ to $60 \%$ of GCA patients have manifestations of PMR [37, 38]. GCA and PMR also share an infectious pathogenetic hypothesis [39].

GCA symptoms include headache, jaw/tongue/limb claudication, scalp tenderness, and impaired vision. Ocular involvement (anterior optic ischemic neuropathy or retinal artery occlusion) is irreversible and can lead to permanent visual loss. Extra-ocular muscle palsies can also rarely occur [39]. The physical examination can reveal thickening and reduced pulsation of the temporal arteries [39]. The laboratory workup shows inflammatory anemia and increased levels of CRP and ESR, though both may be normal in less than $3 \%$ of the patients [39]. Critical for the diagnosis of GCA is the demonstration/examination by the US of the typical "halo sign", a hypoechoic ring around the vasal lumen reflecting edematous thickened artery wall, which is the opposite of the focal hyperechoic wall thickening seen in atherosclerosis [40]. MRI and PET scans can also be useful in assessing whether the vasculitic process has involved vessels other than the temporal arteries [41]. However, the gold standard for the diagnosis is the temporal artery biopsy (TAB). According to the EULAR recommendations, biopsies should be at least $1 \mathrm{~cm}$ in length, which corresponds to a postfixation length of at least $0.7 \mathrm{~cm}$ [6]. Histologic changes are recognizable up to two weeks after starting treatment with GCs [42]. However, several studies have shown that neither imaging nor $\mathrm{TAB}$ is $100 \%$ sensitive $[43,44]$. 
According to the 2018 update of EULAR recommendations for the management of large vessel vasculitis, $40-60 \mathrm{mg} /$ day prednisone-equivalent should be initiated immediately for induction of remission in active GCA. Once the disease is controlled, the GC dose should be tapered to 15-20 $\mathrm{mg} /$ day within 2-3 months and after one year to $\leq 5 \mathrm{mg} /$ day. In patients with a refractory or relapsing GCA or those at an increased risk of GC-related adverse effects or complications, tocilizumab may be used. MTX is another option $[45,6]$.

A subset of patients with GCA is considered to have large-vessel involvement, with radiographic evidence of inflammation in the aorta or its major branches. These patients frequently present with constitutional symptoms, including fever of unknown origin, and may also complain of symptoms suggestive of limb claudication. Compared to patients with classical cranial GCA, those with large-vessel GCA are usually slightly younger, have a longer duration of symptoms, are more likely to experience concurrent PMR at diagnosis, and are less prone to develop vision loss [46]. GCA is profoundly intertwined with cardiovascular complications: atherosclerosis and hypertension. The presence of their risk factors in patients with a new diagnosis of GCA predisposes them to the development of severe ischemic complications [47].

\section{Other Vasculitides}

Anti-neutrophil cytoplasmic autoantibody (ANCA)-associated vasculitis (AAV) affects small vessels and comprises granulomatosis with polyangiitis (GPA), eosinophilic granulomatosis with polyangiitis (EGPA), and microscopic polyangiitis (MPA). Although people of all ages can be affected, $A A V$ is more common in individuals aged older than 60 years, with a slight prevalence in men [48]. AAV is associated with the presence of ANCA to myeloperoxidase (MPO) or proteinase-3 (PR3).

GPA has an annual incidence rate of 2.1-14.4 per million in Europe, with a survival rate of 74$91 \%$ at five years [48]. The disease is characterized by inflammation of the upper and lower respiratory tract and kidneys, with the histological evidence of necrosis, granulomatous inflammation, and vasculitis [49]. The autoimmune process of GPA is mediated by ANCA, mainly those with a positive cytoplasmic staining pattern (c-ANCA), which usually targets PR3, while a perinuclear pattern ( $p$-ANCA) is found in $20 \%$ of the patients and is generally caused by autoantibodies against MPO [49]. In 70-100\% of cases, the initial clinical manifestation is reported in the ear-nose-throat system, especially with the involvement of the nasal cavity and the paranasal sinuses [49]. Though rare, cardiovascular complications, including cardiogenic shock, pericarditis, cardiomyopathy, and coronary artery involvement, have been reported [50].

EGPA has an annual incidence rate of 0.5-3.7 per million in Europe, with a 5-year survival rate of $60-97 \%$ [48]. The median age of onset is $49-59$ years [51]. EGPA is characterized by an eosinophil-rich and necrotizing granulomatous inflammation that often involves the respiratory tract [51] and is associated with a personal history of bronchial asthma and eosinophilia. ANCA, observed in $30-47 \%$ of EGPA patients, are more frequent when glomerulonephritis occurs. Indeed, other than the respiratory tract, kidneys (20-25\% of patients, necrotizing glomerulonephritis) and the peripheral nervous system (mono- and polyneuropathies) can be involved. CRP and creatinine are usually significantly elevated, compared to other forms of vasculitis [51].

MPA has an annual incidence rate of 2.4-10.1 per million in Europe, with a 5-year survival rate of $45-76 \%$ [48]. It is a necrotizing, non-granulomatous vasculitis, with few or no immune deposits. 
Other clinical manifestations include necrotizing glomerulonephritis and pulmonary capillaritis [51], with alveolar hemorrhage [52].

Current treatment strategies for severe AAV, supported by randomized control trials, aim to achieve remission with high-dose GCs and either rituximab (an anti-CD20 chimeric monoclonal antibody) or cyclophosphamide, followed by relapse prevention with sustained low-dose treatment. This approach has dramatically improved outcomes in AAV; however, a significant proportion of patients experience serious treatment-related side effects or suffer relapse [53].

Another vasculitis potentially affecting the elderly is polyarteritis nodosa, which involves medium vessels. Like other vasculitides, it is a very heterogeneous disease characterized by cutaneous, vascular, and neurological involvement. An association with the hepatitis B virus is notably reported [54].

One of the overarching principles of the 2018 EULAR recommendations for the management of large vessel vasculitis underlines the necessity of screening for cardiovascular comorbidities [6]. The pivotal importance of lifestyle advice to prevent and reduce cardiovascular risk in such patients is also stressed $[6,53]$.

\section{Crystal-induced Arthritis}

Crystal-induced arthritis is characterized by the deposition of crystals in and around the joints and can affect older adults. Different types of crystals can be found in synovial fluid (SF). The crystals capable of inducing arthritis are constituted of monosodium urate (MSU), which is typical of gout, calcium pyrophosphate dihydrate (CPPD), associated with a variety of clinical presentations, including acute pseudogout, and basic calcium phosphate (BCP; hydroxyapatite, octacalcium phosphate, and tricalcium phosphate), which can be observed in as much as $60 \%$ of samples from osteoarthritic joints [55].

\subsection{Gout}

Gout is a chronic, systemic disease resulting from the deposition of MSU crystals in and around the joints as a consequence of persistent hyperuricemia [56]. It affects almost $4 \%$ of adults in the USA [57], 0.9\% in France and Italy, 2.5\% in the UK, 1.4\% in Germany, and $3.2 \%$ to $6.1 \%$ in New Zealand, where $3.2 \%$ refers to those with European ancestry and $6.1 \%$ to Maori ancestry, suggesting a genetic background $[57,58]$. The incidence of the disease has increased over the last few years, progressing from 0.30 per 1000 person-years in the 1970 s to 2.68 per 1000 personyears in the 2000s in the UK and USA [57]. While it seems to be more frequent in men (2- to 6fold) [59], the peak age is 70 years for both genders [57]. However, it may also affect young people, especially when associated with genetic mutations [57].

The disease can be classified into renal overload (ROL) gout and renal underexcretion (RUE) gout [60]. A genetic predisposition to gout has been highlighted by genome-wide associated studies (GWAS) [60].

Among non-genetic risk factors, the role of some drugs (diuretics, angiotensin-converting enzyme inhibitors, $\beta$ blockers, non-losartan angiotensin II receptor blockers, cyclosporine, tacrolimus, ritonavir, pyrazinamide) and foods (red meat, alcohol, seafood, sugar-sweetened, and fructose-rich beverages) $[57,61]$ is well known. Increased urate formation may also derive from an 
exaggerated cellular turnover, as it may occur in psoriasis and malignancies [57], which have an increased prevalence in elderly people.

Asymptomatic hyperuricemia and MSU crystal deposition precede the onset of clinically overt acute gout [57]. Hyperuricemia becomes pathological above MSU levels of $6.8 \mathrm{mg} / \mathrm{dL}$; beyond this threshold, MSU starts to form and deposit in many tissues [57]. The solubility of uric acid and capacity to form MSU crystals are influenced by many factors, such as SF pH, water concentration, electrolyte levels, the integrity of intraarticular proteoglycans, and collagen [59]. MSU crystals interact with resident macrophages, prompting the activation of the NLRP3 inflammasome that leads to the production of IL-1, via caspase 1 activation [57]. Following the asymptomatic deposition of crystals inside the joints, an acute flare of gout may occur [57]. This is often monoarticular, accompanied by a violent pain associated with all other typical signs of inflammation. It peaks within $24 \mathrm{~h}$, usually appearing at night, when lower temperatures facilitate the precipitation of crystals [57, 59]. In most cases, it affects the first metatarsophalangeal joint, but also knees, ankles, wrists, and metacarpophalangeal (MCP) joints [59]. Bursitis and tendonitis, fever, headache, and malaise may be present [59]. The acute gouty attack may self-resolve in 1-2 weeks [57], but further attacks may suddenly develop and also become more frequent and severe if proper treatment for hyperuricemia is not started. The asymptomatic period between acute phases is called the intercritical period [59]. Chronic gout is characterized by synovitis in multiple joints, cartilage damage, bone erosions, and tophi, which are formed by accumulated crystals mixed-up with collagen and other debris from previous inflammation [57, 59].

Apart from joints, tophi may be found in the viscera, spine, and subcutaneous tissues [57-59], where they may ulcerate, leading to the excretion of white, chalky material and possible infection.

In 2015 ACR/EULAR investigators elaborated criteria for the classification of gout [58].

The gold standard for gout diagnosis is the presence of MSU crystals in the SF [57-59], with $100 \%$ specificity [62]. MSU crystals are identified by compensated polarized light (CPL) microscopy $[57,59]$. They appear needle shaped under simple light microscopy, strongly birefringent under a polarized microscope, and show a negative birefringence or elongation in CPL microscopy [57, 59]. Culture and cell count analysis of the SF shows predominance of polymorphonucleates that may exceed 50000 cells $/ \mu \mathrm{L}$. No bacteria are found, but culture must always be performed to formulate a differential diagnosis with septic arthritis (SA), especially when the onset of gout is monoarticular [59]. Hyperuricemia is not a proper marker for gout during a gouty attack, because its levels may be normal [62]. Other nonspecific findings commonly found in gout are elevated acute phase reactants and neutrophils count [57]. US shows several features, including a hyperechoic enhancement on the surface of the articular cartilage, known as the double contour sign, some hyperechoic foci floating in the joint space (snowstorm appearance), and tophi, as hyperechoic aggregates in the joint or along with tendons [62], which are surrounded by an anechoic rim [57]. Erosions in advanced gout can also be found and confirmed in two perpendicular planes with the US and conventional radiography (CR) [57, 59]. Dual-energy CT (DECT) evaluates the difference in attenuation of a material exposed to two distinct $X$ rays spectrums, creating a colored map of the urate deposits, with $87 \%$ sensitivity and $84 \%$ specificity [57].

The 2016 EULAR recommendations and 2020 ACR guidelines provide an update on the treatment of the disease. In compliance with EULAR recommendations, flares should be neutralized by using colchicine, non-steroidal anti-inflammatory drugs (NSAIDs), oral or intra- 
articular GCs, or even using a combination of these drugs. In patients with frequent flares and contraindications to the above-mentioned drugs, an IL-1 inhibitor should be considered. Once the flare is controlled, urate-lowering therapy (ULT) is crucial to maintain serum uric acid levels at $<6$ $\mathrm{mg} / \mathrm{dL}$ or $<5 \mathrm{mg} / \mathrm{dL}$ in severe gout. Allopurinol is recommended as the first-line ULT; as an alternative, febuxostat or the combination of a xanthine oxidase inhibitor with a uricosuric should be considered. For patients with refractory gout, pegloticase is recommended. Besides, EULAR recommendations focus on the education of the patients and the assessment of comorbidities [63]. Hypertension, hyperlipidemia, diabetes mellitus, and cardiovascular events are all associated with gout. It is reported that this disease carries about $50-70 \%$ increased risk of cardiovascular disease compared with the general population [64]. Moreover, high levels of uric acid were shown to be important predictors of frailty in older adults [65].

\subsection{Calcium Pyrophosphate Deposition Disease (CPPD)}

CPPD is one of the most common rheumatic diseases occurring in people over 60 years of age [66]. The prevalence of CPPD ranges from $4 \%$ to $7 \%$ of the adult population in Europe and the USA and increases with advancing age $[67,68]$. As outlines in EULAR guidelines, CPPD is the umbrella term for all forms of CPPD, which may occur as chondrocalcinosis, an asymptomatic condition associated with OA, acute arthritis (also known as pseudogout), or chronic arthritis [69].

Apart from age, many other risk factors including OA, hemochromatosis, concurrent gout, previous trauma, meniscectomy, conditions involved in the inorganic pyrophosphate (iPP) metabolism (hypophosphatasia, hypomagnesemia, hyperparathyroidism), intraarticular preparations of hyaluronic acid, and systemic medications (pamidronate, loop diuretics and granulocyte-macrophage colony-stimulating factor) play a role in the development of CPPD [68].

CPPD pathogenesis is based on the formation of CPP crystals from extracellular iPP in pericellular matrix of cartilage [68]. iPP derives from extracellular adenosine triphosphate (ATP) efflux, which is regulated by the membrane protein human homolog of the protein product of the murine progressive ankylosis homolog gene (ANKH), found in articular cartilage, in the meniscus and synovium [70]. ATP extruded from the cell by the ANK transporter is metabolized by ectonucleotide pyrophosphatase phosphodiesterase 1 (ENPP1) to iPP $[66,68]$. Interestingly, ENPP1 activity increases with age and in patients with OA [66]. Some pyrophosphatases and alkaline phosphatase, instead, degrade iPP. CPP crystals are formed from the binding of extracellular iPP and calcium. Crystals can then activate the NLRP3 inflammasome and start inflammation, similarly to gout, by production of the destructive matrix metalloproteinases (MMPs) and prostaglandins which alter the integrity of cartilage [68].

Pseudogout, the acute CPP crystal arthritis, is characterized by the acute onset of mono- or oligo-articular arthritis, commonly involving knees or wrists that may last for weeks [68]. The main differential diagnosis is gout and SA, which must be excluded in the diagnostic process. Chronic CPPD can affect shoulders, wrists, and MCP joints, or even simulate RA [68]. Crowned dens syndrome is caused by the deposition of CPP crystals around the C2 vertebra and is characterized by acute severe neck pain, fever, and elevated levels of inflammatory markers [71]. The diagnosis of CPPD requires SF analysis, CR, and US. SF analysis should be performed with CPL microscopy, which reveals the presence of rhomboidal crystals with a positive elongation and wide range (from none to quite brilliant) of birefringence, though about $80 \%$ of CPP crystals do not show any 
birefringence [68]. CR can identify chondrocalcinosis, by detecting calcifications within the joint space of the affected sites [68]. US is also useful in identification of hyperechoic calcifications in the fibrocartilage (menisci, triangular fibrocartilage of the wrist), hyaline cartilage (knees and MCF), tendons, and SF (hyperechoic spots) [67].

EULAR experts delivered recommendations for the management of CPPD, and indicated both non-pharmacological and pharmacological intentions. For acute CPPD, cool packs, temporary rest, and joint aspiration combined with GC injection should be applied. For prophylaxis or chronic disease, oral NSAIDs with gastroprotective treatment and/or low-dose colchicines ( 0.5-1.0 mg daily) may be used. Parenteral or oral GCs for acute CPPD in patients who are unresponsive or unsuitable for other measures, and low-dose GCs, MTX, or hydroxychloroquine for chronic CPPD is advised, while for asymptomatic CPPD, no treatment is suggested [72].

\subsection{Basic Calcium Phosphate Crystal Deposition Disease}

BCP deposition (BCPD) disease has a peak age of incidence that spans from the fourth decade till death (beyond the sixth decade of life) [73]. A Swedish study unearthed low prevalence of BCPD in a southern region of Sweden $(0.23 \%)$ and evidenced higher occurrence in people above 80 years of age [74].

The disease pathogenesis is not well understood. Mild trauma or overuse of the joints with autoimmune, and metabolic conditions are associated with spontaneous onset in most cases [75].

Calcific deposits can be found in all peri-articular soft tissues, including in the tissues of arteries, skin, breast, etc. [76]. These deposits may be asymptomatic or express several clinical syndromes. Among these, acute calcific periarthritis of the shoulder, characterized by a rapid onset of severe pain, swelling, and restriction of motion, is the most frequent [77]. Calcific tendinitis of the hip causes monoarticular pain and restriction of joint movement similar to acute hip arthritis, although acute calcific periarthritis tends to resolve within 2-3 weeks [77]. Regarding the genesis of calcific periarthritis, it is believed that the rupture of pre-existing calcific deposits causes their transport into adjacent soft tissue spaces, with subsequent acute inflammatory reaction [78].

A peculiar and very severe condition associated with BCP crystal deposition is the Milwaukee shoulder syndrome (MSS), which can occur in patients between 60 and 90 years of age, due to intra-articular deposition of BCP crystals that release lysosomal enzymes leading to the destruction of articular and peri-articular structures, including the rotator cuff [79]. Apart from shoulders, other joints, including the knees, hips, and/or elbows, might be involved [80]. Patients with MSS typically have large, synovial effusions with abundant aggregates of BCP crystals [76]. However, individual BCP crystals are non-birefringent and are too small to be detected by conventional or polarized light microscopy [81]. Furthermore, despite their tendency to clump, especially when present in large amounts, BCP crystals remain undetectable in the SF [66], which is usually noninflammatory with a low leukocyte count [79]. US, CR, CT, MRI, and DECT can all be helpful for the diagnosis [82].

Treatment of CPB crystal deposition disease is based on NSAIDs, colchicine, GC injections, rest, physiotherapy, and even surgery in advanced arthropathies $[79,83]$. 


\section{Osteoarthritis (OA)}

$\mathrm{OA}$ is a disease of aging more frequently observed in women than men after the age of 50 years [84]. Among the many definitions provided, one from the American Academy of Orthopedic Surgeons appears mentionworthy and extensive: "OA is the result of both mechanical and biological events that destabilize normal coupling of degradation and synthesis of articular cartilage and subchondral bone. Although it may be initiated by multiple factors, including genetic, developmental, metabolic, and traumatic, $O A$ involves all of the tissues of the diarthrodial joint. Ultimately, OA is manifested by morphologic, biochemical, molecular, and biomechanical changes of both cells and matrix, which lead to softening, fibrillation, ulceration, and loss of articular cartilage, sclerosis, and eburnation of subchondral bone, osteophytes, and subchondral cysts. When clinically evident, $\mathrm{OA}$ is characterized by joint pain, tenderness, limitation of movement, crepitus, occasional effusion, and variable degrees of local inflammation" [85].

OA shows a high prevalence across the world. Globally, the World Health Organization (WHO) estimated that $10 \%$ to $15 \%$ of all adults, aged over 60 years, have some degree of OA, with $9.6 \%$ of men and $18 \%$ of women aged over 60 years having the a symptomatic disease (https://www.who.int/chp/topics/rheumatic/en/). The prevalence of OA, however, varies greatly depending on the definition used, age and gender of the patient, and geographical area studied [86]. Incidence depends on the committed joint and is estimated to be $240 / 100,000$ person-years for knee OA; 100/100,000 person-years for hand OA; and 88/100,000 person-years for hip OA in the USA [87].

OA negatively affects patients' quality of life, with a burden similar to that of RA accounting for 2.4\% of all years lived with disability (YLD) [88]. Between 1990 and 2013, a 75\% increase was seen in OA-related YLDs worldwide, making the disease the third most rapidly rising condition associated with a disability after diabetes and dementia [7]. As a consequence, OA consumes a high rate of healthcare resources, both directly (hospitalization, emergency room visits, physician visits, outpatient visits, and medications) and indirectly (absenteeism, presenteeism, disability, and worker's compensation) [89]. It has been estimated that OA accounts for $1 \%$ to $2.5 \%$ of the gross national product of some countries, such as France, Canada, the UK, and the USA [89].

The pathogenesis of OA is complex and in completely understood. Genetic factors are involved, as demonstrated by epidemiological studies, linkage studies, candidate gene approaches, and genome-wide association studies [90]. It was recently hypothesized that the disease is the consequence of the balance of two types of inflammation, i.e., mechanoflammation, due to mechanical stress, and metaflammation, caused by metabolic stress. Mechanoflammation leads to local inflammation driven by regional trauma with subsequent activation of proteolytic enzymes, such as MMPs. On the other hand, metaflammation is a chronic, systemic low-grade inflammation led by adipokines discharged from adipose tissue. In obese people, these two types of inflammation work together and reinforce each other [91, 92]. The sentence should be like this: Typically, the response to injury branches off across repairing mechanism, largely driven by transforming growth factor $\beta$ (TGF $\beta$ ) and fibroblast growth factor 2 , and a destructive mechanism. The latter is mediated by TGF $\beta$-activated kinase 1 (TAK1), which lies upstream of the inflammatory mitogen-activated protein kinases, bringing to the release of nerve growth factor, a mediator of pain [93] and other pro-inflammatory molecules, such as tumor necrosis factor (TNF), 
IL-1 and IL-7 [94]. These stimulate the production of MMPs, with a dominant role taken by MMP-1 and MMP-13 [95], which is responsible for the degradation of type II collagen [96].

OA affects the axial skeleton as well as peripheral joints, mainly hands, knees, and hips that can be radiologically and clinically classified according to ACR criteria [84]. The natural history of OA can vary greatly. OA generally develops progressively, although symptoms may remain relatively stable for prolonged periods. Still, flares can occur during the disease [97 ]; in such cases, inflammatory arthritis, infection, and crystal-induced arthropathies should be excluded. Furthermore, the correlation between clinical outcomes and the radiographic course is rather poor, and not all radiologically affected joints are symptomatic [98].

The main symptom of $O A$ is pain, typically exacerbated by joint use and relieved by rest. However, with disease progression, pain occurs even at rest and finally, during sleep. Because cartilage has no nerve supply, pain is likely to arise from other articular and peri-articular tissues, but central pain processing is also altered in patients with OA [99]. Stiffness in the morning or after periods of inactivity is another feature of the disease, which tends to resolve within 15 min. Limitations of function develop as the disease progresses, and patients report significant deterioration in the quality of life and experience limitations in performing day-to-day activities, such as walking, fulfilling household duties, kneeling, and climbing the stairs. The physical examination reveals bony swelling, joint tenderness, crepitus on passive or active movement of a joint, and finally joint deformities. The blood tests are not routinely indicated to confirm the diagnosis since they are usually within the normal range [84]. A EULAR task force developed evidence-based recommendations on the use of imaging in patients with symptomatic and peripheral joint OA [100]. According to these recommendations, imaging should only be performed in atypical presentations to confirm the diagnosis or in cases of unexpected rapid progression of symptoms or change in clinical characteristics to ascertain disease severity or the presence of an additional diagnosis. If imaging is neede7d, CR should be preferred, while US or $\mathrm{MRI}$ are indicated to make additional diagnoses for soft tissues and CT or MRI for bone [100].

Treatment of $O A$ is aimed at reducing pain and stiffness while maintaining functional capacities. To this purpose, non-pharmacological (education and information access, support for selfmanagement, exercise, weight loss, biomechanical aids, and appliances), pharmacological (paracetamol, oral or topical NSAIDs, opioids, intra-articular GCs or hyaluronan, nutraceuticals, duloxetine), and surgical options, even in combination, may be applied according to individual needs and risk factors. Their use is tuned by the recommendations from experts of international organizations, including EULAR, the Osteoarthritis Research Society International, and the National Institute for Health and Care Excellence (NICE) [101-106]. Notably, no drug is currently recommended for modification of OA due to limited evidence. Treatment of depression, which is frequent comorbidity, is important and may be targeted by using low-dose amitriptyline at night in patients with non-restorative sleep because of pain. Symptomatic OA is strongly associated with frailty in the elderly, with a three-fold increase in risk compared to the non-symptomatic OA population. The prevalence of frailty in OA patients aged 65-85 years old is estimated to be around $10.4 \%$ in Europe [107]. 


\section{Osteoporosis}

Osteoporosis (OP) is a systemic skeletal disorder defined by WHO in 1994 as "a generalized bone disease characterized by a decreased bone mass and a deterioration of bone microarchitecture resulting in an increased fracture risk" [108]. In 2001, the US National Institute of Health $(\mathrm{NIH})$ defined OP as "a disease of compromised bone strength, resulting in an increased risk of fracture" [109]. Both definitions highlight the uniqueness of a clinical condition being at the same time disease and a risk factor. For epidemiological purposes, WHO allows a diagnosis of OP to be made when the bone mineral density (BMD) measured by dual-energy X-ray absorptiometry (DXA) is lower than -2.5 standard deviation below the mean peak BMD in young healthy adults of the same gender, which is also known as T score [110]. Primary OP may occur after menopause (postmenopausal OP) or with advancing age (senile OP). The prevalence of OP ranges from $22.2 \%$ to $33.2 \%$, depending on the bone evaluated, but most women with OP are asymptomatic, which makes epidemiological research difficult [111]. Osteoporotic fractures have important social and economic effects since the fragility fractures are associated with increased mortality and morbidity. Death is directly related to hip fracture in $24 \%$ of cases, and $28 \%$ of deaths in patients hospitalized for vertebral fractures are thought to be secondary to the fracture itself [112]. Fractures of the hip, vertebrae, and wrist are considered as the typical osteoporotic fractures, although prospective studies have shown an increased risk of almost all types of fractures in case of low BMD [113]. Moreover, adults experiencing a fracture are at greater risk of having a subsequent fracture $[113,114]$. Between 55 and 75 years of age, the risk of vertebral fractures in postmenopausal women is higher than by any other type of fracture, but at the age of $>75$ years, the risk of hip fracture and other non vertebral fractures also increases [115]. Apart from a reduction in BMD, aging and previous fragility fractures, risk factors for OP and related fractures include female gender, current cigarette smoking, family history of hip/vertebral fractures, alcohol intake, vitamin D deficiency, early menopause (before the age of 45 years), low physical activity, several chronic diseases and drugs (GCs, aromatase inhibitors, gonadotropin-releasing hormone agonists, selective serotonin recapture inhibitors, antiepileptic drugs, proton pump inhibitors) [116]. Special attention should be given to interventions that reduce the risk of falls in the elderly by improving home safety [117]. It is well known that OP derives from the altered balance between reabsorption and new deposition of bone. The most important role is played by osteoblasts and osteoclasts. Osteoblasts derive from mesenchymal stem cells, and their role is to favor bone regeneration. Their activity is enhanced by TGF $\beta, I L-4, I L-10, I L-13$, and IL-18. These molecules stimulate osteoblasts activity, favor their proliferation, block apoptosis, and induce elevation of osteoprotegerin. On the other hand, bone reabsorption is run by osteoclasts. Activated macrophages and cytokines such as TNF, IL-1 $\beta, I L-6$, and M-CSF promote osteoclast differentiation, proliferation, and activity, but the most important stimulus is given by the receptor activator of nuclear factor $\mathrm{KB}$ ligand (RANKL), which stimulates osteoclasts into mature multinucleated osteoclasts [118]. Even hormones can influence the balance between bone promotion and bone reabsorption. In particular, parathyroid hormone (PTH) triggers both resorption and formation, ultimately leading to promote bone mass. Vitamin $D$ has a protective role as well. Other hormones can favor or induce OP, such as GCs, or protect the bone (estrogens) [119]. 
The treatment of OP combines the need to remove preventable risk factors together with nonpharmacological interventions (physical activity, correction of poor protein intake) and the use of drugs with proven anti-fracture efficacy. Most of these drugs decrease osteoclastic activity (bisphosphonates, selective estrogen-receptor modulators, denosumab), while teriparatide is the only bone anabolic agent available. Bisphosphonates are the first-line therapies for most patients with OP. Selective estrogen-receptor modulators (SERMs) are non-steroidal agents that bind to the estrogen receptor and act as estrogen agonists or antagonists, depending on the target tissue $[120,121]$. Denosumab is a humanized monoclonal antibody that binds selectively and with highaffinity RANKL expressed by osteoblasts, hindering the engagement of RANK on osteoclasts [122]. Teriparatide is a form of PTH given as daily subcutaneous injections. Interestingly, this intermittent administration of PTH increases the number and activity of osteoblasts, leading to an increase in bone mass and an improvement in skeletal architecture [123]. Adequate calcium and vitamin D intake is essential in all pharmacological approaches to limit the risk of hypocalcemia [124]. OP, with its high burden of disability, is strongly connected to frailty due to low levels of BMD. On the other hand, frailty is strongly associated with a significant risk of recurrent falls and, subsequently, of death $[125,126]$.

\section{Septic Arthritis}

SA is caused by the presence of a bacterial agent within a joint. The infection can reach the joint from the blood flow, from infected contiguous foci, from neighboring soft-tissue sepsis, or by direct inoculation due to trauma or an iatrogenic event. SA should be promptly recognized and treated due to its potential to cause rapid joint destruction [127]. The overall estimated incidence of SA in the general population is about 2-10 cases per 100,000 person-years in industrialized countries, but an increase has been observed over the last years [128, 129]. SA shows two peaks, one below five years of age and the other over 64 years, without significant gender differences [130]. According to some studies, around $60 \%$ of cases are diagnosed in 60 -year-old persons or older [131]. This may be explained by several factors, such as increased orthopedic procedurerelated infections, aging population, and more frequent use of immunosuppressive therapies [129, 132,133 ]. The main risk factors for SA include age $>80$ years, cardiovascular diseases, such as coronary artery disease, congestive heart failure, and chronic pulmonary obstructive disease, the presence of prosthetic joint, recent joint surgery, skin infection, prior intra-articular therapeutic injections; immunosuppression due to diabetes, renal and liver diseases, drugs, human immunodeficiency virus infection, alcohol abuse, cancer, and RA [128, 134-138]. Interestingly, patients with RA have an approximately 10-fold-higher incidence of SA than the general population [127]. A significant increase in the mortality rate in elderly adults both at six months and at 1-2 years after the infection has been observed [134]. SA typically presents as an acute, very painful monoarthritis with fever. Irreversible loss of joint function develops in $25-50 \%$ of patients, generally because of delayed diagnosis and treatment. If SA is suspected, arthrocentesis of the joint is mandatory; the SF is analyzed for Gram stain, white blood cell count, and cultured for bacteria. Gram-negative organisms are more common in older patients and immunocompromised patients. However, the sensitivity of Gram staining to detect the infection is limited, being positive in 71\% of Gram-positive SA and $40-50 \%$ of cases of Gram-negative SA [139]. Laboratory markers of systemic inflammation have only a limited diagnostic value due to low 
sensitivity [140]. Imaging may be of help in supporting the diagnosis. In later stages, CR may reveal juxta-articular OP, diffuse joint space narrowing due to cartilage destruction and erosions, and finally destruction of the joint [127]. Musculoskeletal US may show non-echo-free effusions, characteristic of the disease, while MRI aids in early diagnosis of SA because of high resolution for soft-tissue abnormalities [141].

Prompt treatment with parenteral antibiotics without waiting for the results of bacterial cultures should be initiated. The choice of antibiotic is empirical, based on the likelihood of the organism involved. When the culture results are available, antibiotics can then be chosen according to the sensitivity pattern, starting with intravenous treatment for 10-14 days, often followed by oral antibiotics for minimum six weeks. Needle aspiration is recommended to support antibiotic therapy. More invasive procedures, such as arthroscopy and drainage, can be adopted if the infection is resistant to medical treatment to preserve joint function and limiting joint destruction [142]. Arthrotomy should be performed when urgent decompression of the joint is needed or, in particular circumstances, to make the etiologic pathogen more attackable by the action of antibiotics [143]. While the surgical approach in the case of prosthetic joint infection is generally accepted to obtain better absorption of antimicrobial agents [133], indications are less fruitful for native joints [142]. Moreover, NSAIDs or analgesics, unloading of the affected joint, and physiotherapy to prevent muscular atrophy and contractures should all be considered.

\section{Elderly-Onset Rheumatoid Arthritis}

RA is a chronic, autoimmune, inflammatory joint disease responsible for persistent synovitis with cartilage and bone destruction and consequent development of disability. Despite the prevalent joint involvement, RA should be considered a syndrome characterized by extra-articular manifestations, including rheumatoid nodules, pulmonary involvement or vasculitis, and systemic comorbidities [144]. Disease onset usually occurs between the 4th and the 5th decade of life. Term elderly-onset RA (EORA) describes the disease with an onset at age over 60 [145]. The proportion of elderly patients with RA is continuously growing as a result of the increasing aging population. The incidence of EORA in Spain was reported to be 14.5-15.3 for females and 9.1-15.8 for males per 100.000 population [146]. Prevalence in the USA has been estimated to be around $2 \%$ in persons with at least 60 years of age [147].

The hypothesis of different pathogenesis for EORA is supported by the evidence of a diverse clinical picture, including higher recognition of overlapping manifestations with PMR and RS3PE $[145,148]$. Due to the high prevalence of patients with inflammatory involvement of shoulders, the differential diagnosis between EORA and PMR is quite challenging, and in these cases, the presence of anti-citrullinated protein/peptide antibodies (ACPA) is highly suggestive of RA [149]. Nonetheless, in patients with EORA, there is a lower prevalence of autoantibodies compared to young-onset rheumatoid arthritis (YORA) $[148,150]$. Although the presence of autoantibodies in RA is generally associated with a worse disease outcome, a higher frequency of acute disease onset especially in patients with EORA and negative RF has been observed [151]. A diverse genetic background between EORA and YORA has been found. As known, the human leukocyte antigen (HLA)-DRB1 named "shared epitope" is an important genetic risk factor for RA development, and its presence is associated with a specific disease phenotype $[152,153]$. Both the shared-epitopecoding alleles and the HLA-DQ*04 were less frequently found in EORA patients compared to YORA 
[154]. Additionally, in a study conducted on RA Colombian patients, HLA-DRB1*0403 and *1402 were more frequent in the elderly than in young patients [150]. A different distribution of the DRB1 genotypes between YORA and EORA patients has also been demonstrated in a Japanese population [155].

The diverse pathogenic background between EORA and YORA is further supported by a different serological profile. In patients with EORA, higher IL-6 and lower TNF serum levels have been documented. Interestingly, extremely high serum levels of IL-6 were mostly detectable in elderly patients with PMR-like symptoms [156]. These findings need to be considered when choosing among the spectrum of the currently available therapeutic strategies for RA. In the past decades, different studies underlined the existence of clinical and serological differences between patients with EORA and those with YORA $[145,148,151]$. In contrast with YORA, which mainly occurs in women, in EORA, a balanced gender distribution has been reported, with evidence of a clinical course characterized by important systemic features, higher disease activity, and more pronounced inflammatory parameters $[145,148,151]$. Also, compared to YORA, EORA shows more common involvement of large joints 145, 148, 151], and a higher frequency of distalproximal involvement seems characteristic [150]. Additionally, a fast-radiographic progression with advanced destructive changes is quite frequent and seems more evident in patients with positive autoantibodies [145]. Interestingly, cardiovascular risks, as well as disability, have been demonstrated to depend on disease duration and not on the age, at which the patient develops AR. On the other hand, EORA has a significant association with cardiovascular comorbidities [157].

The treatment of EORA pursues the same objectives as in younger patients, including the achievement of remission or at least a low disease activity and the prevention of structural damage [158]. However, the presence of comorbidities in elderly RA patients is not a negligible aspect, and the occurrence of drug-related adverse events is quite frequent [159]. The prescription of GCS is a remarkable approach in clinical practice, and its use in EORA is more common than MTX and biologic drugs [148]. However, the role of GCs is still controversial, as their short-term symptomatic relief and potential medium-term effects on structural damage are counter-balanced by their side effects. In the elderly, MTX is effective and, despite possible limitations due to renal impairment, it does not seem to be less tolerated than in younger patients [160]. Finally, biological agents are largely and successfully administered, although in the elderly, the use of anti-TNF agents seems slightly less effective, and the frequency of adverse effects is a bit higher. Nonetheless, similar findings were shown from conventional disease-modifying treatments in another study [160]. RA patients tend to develop frailty at a younger age and with a severe prognosis. The prevalence of frailty in patients with RA over 60 years of age is approximately $36.4 \%$ greater than that of the general population which is around $14-16 \%$ for the same age span. The main factors associated with frailty in this cohort of patients were age, disease activity, and comorbidity burden [161].

\section{Sjögren's Syndrome}

Sjögren's syndrome (SS) is a systemic autoimmune condition characterized by chronic inflammation of exocrine glands. The presence of sicca symptoms, including xerophthalmia and xerostomia, is the hallmark of the disease and mostly represents the first clinical sign at disease onset [162]. SS mainly affects middle-aged people and a late-onset is considered as a disease 
appearing after age 65 [163]. However, the age cut-off used to identify patients with a late disease onset is not univocal being also reported in 50-, 60, or even 70- year-old individuals [163]. Although SS is highly prevalent among middle-aged individuals, elderly patients account for up to $20 \%$ of SS cases $[163,164]$. A systematic review of all the epidemiological studies on primary SS published up to October 2013 found a global prevalence rate of 60.82 (95\% Cl 43.69 to 77.94 ) cases per 100000 inhabitants with a female/male ratio of 10.72 (95\% Cl 7.35 to 15.62). [165].

In the elderly population, SS is one of the most under-diagnosed conditions, as sicca symptoms are frequently attributed to medications and/or aging. When considering SS diagnosis in the elderly, it is important to obtain a thorough drug history as the use of tricyclic antidepressants and antipsychotic drugs can frequently cause dryness. In a population-based study of elderly individuals, approximately $27 \%$ of the participants reported dry eyes or dry mouth, and among them, about $62 \%$ were related to the use of concomitant medications [166]. It is also important to remind that exocrine glands naturally undergo histological changes with time, including acinar atrophy, fibrosis, and ductal dilatation, which are all responsible for a reduction in secretory function [167]. Hence, standardized histological diagnostic criteria have been developed to identify lip biopsy displaying histological features indicative of SS [168]. These include the presence of lymphocytic infiltrates measured by the focus score calculation [169] as well as the identification of germinal center-like structures [170].

The incidence of Xerostomia in the elderly population is estimated to be $17 \%$ [171], and, in a previous study, SS was suggested as an underlying cause in approximately 40\% of patients [164]. To the same extent, dry eye symptoms are fairly frequent in older people, as demonstrated in 62 healthy elderly individuals, where $22 \%$ were found to have an abnormal Schirmer's test [172].

As stated by the American-European classification criteria [173], the detection of anti-Ro/SSA and anti-La/SSB antibodies is important for SS diagnosis. However, compared to young SS patients, in the elderly, a lower prevalence of serological manifestations was found [174, 175]. For instance, in 17 patients with SS with a median disease onset of 71 years, RF and anti-Ro/SSA antibodies were significantly less common compared to 68 young patients; in the same study, despite the lack of statistical significance, the elderly onset group also presented milder clinical symptoms [174]. Accordingly, SS patients with early disease onset ( $<35$ years old) presented a higher prevalence of lymphadenopathy, rheumatoid factor, anti-Ro/SSA antibodies, and monoclonal immunoglobulins as compared to patients with the late- onset disease [176]. However, in a previous study on 31 patients with late-onset SS (>70 years old), the prevalence of immunological features, as well as glandular and extra-glandular manifestations, was similar compared to the young-onset group [175]. The lack of agreement arising from these studies is possibly related to different age cut-offs used to distinguish the elderly from young patients.

As reported in the most recent recommendations, management of SS involves both treatment of dry eyes and dry mouth with local replacement and/or stimulation therapies and, in case of serious systemic involvement, the use of immunosuppressive therapies [177]. In the elderly, medications may have limited use because of potential comorbid conditions and multiple concurrent medications. Additionally, in these patients, an increased rate of adverse events related to therapeutic agents has been described with consequent need of a careful follow-up in most of them [178]. For instance, the use of stimulation therapies, such as pilocarpine, is limited by adverse effects, including sweating, flushing, abdominal pain, headache, and increased urination and is contraindicated in patients with ischemic heart disease [178]. Additionally, the use 
of immune-suppressive agents in the elderly may be burdened by increased infectious risk [178]. However, the treatment of SS in the elderly does not differ from that in younger patients and aims to control glandular and extraglandular manifestations, to prevent damage to organ systems, and to decrease morbidity and mortality [179]. In SS, subclinical atherosclerosis has been reported in half of the patients; thus, enhancing the importance of prompt screening [180-181].

\section{Late-onset Systemic Lupus Erythematosus}

Late-onset SLE (LSLE) presents some peculiarities in clinical features, autoimmunity profile and disease course compared to younger patients, even though data from various studies are not always consistent $[182,183]$. LSLE refers to patients who receive a diagnosis of SLE after the age of 50 years. It is reported to occur in 3-18\% of SLE patients, with a lower male-to-female ratio (1:2.6) than in the adult-onset group (1:13) [184, 185]. LSLE is characterized by serositis, pulmonary involvement, and secondary SS, all of which appear more frequently than in adult-onset SLE. Moreover, the first manifestations are usually weakness, fatigue, weight loss, while arthritis, cutaneous manifestations (such as photosensitivity and malar rash), Raynaud's phenomenon, lymphadenopathy, renal involvement show a lower incidence $[184,186,187]$. LSLE patients present a lower incidence of hypocomplementemia, lower rates of anti-dsDNA and anti-Sm antibody positivity, and no differences in anti-SSA and anti-SSB antibody positivity rate compared to adult-onset SLE [184]. In an age-stratified Caucasian population, no significant differences were found among groups, except a more frequent peripheral nervous system involvement and the more frequent finding of anti-dsDNA antibody and RF positivity in patients $\geq 65$ years [183]. LSLE is believed to have a mild course with a low number of flares and low disease activity, but the accumulation of organ damage does not differ from adult-onset SLE. As a consequence, LSLE does not have a lower mortality rate, probably due to the burden of comorbidities $[188,189,190]$, mainly hypertension and diabetes mellitus $[187,188]$, while infectious diseases are reported to be the first cause of death [191]. In a Colombian study, a higher incidence of HLA-DR17 (DR3) in patients with LSLE was observed compared to patients without autoimmune diseases [192], in accordance with the finding that DR3 haplotype is linked to a strong risk of SLE susceptibility [193]. Lower use of GCS is reported in LSLE patients, while adequately validated data are lacking on the use of immunosuppressants [182, 185, 186, 194]. SLE patients seem to be more prone to develop frailty at a younger age than the general population. The prevalence of frailty was estimated at around $20 \%$, much higher than in the general population, implying a higher risk of death and disability [195].

\section{Discussion}

More than half of older people experience multimorbidity [196], with musculoskeletal conditions representing one-third to more than one-half of all non-communicable disease multimorbidity [197]. The current study has relevant socioeconomic implications since several rheumatic conditions are among the most disabling diseases, concurring to global frailty and posing major threats to healthy aging by limiting physical and mental capacities and functional ability. Indeed, musculoskeletal conditions significantly contribute to global disability, second only to mental health conditions [7]. This perspective prompted the current useful review, aimed at providing an abridgment of the popular rheumatic conditions typically observed in the elderly. The 
knowledge of these diseases and related issues beyond the rheumatology community constitutes a critical step for prompt and proper referral of patients to ameliorate their overall long-term outcome.

\section{Conclusion}

In the current review, a broad spectrum of more than 50 rheumatic diseases is covered. More than 150 rheumatic diseases affect during various stages in life, especially from the 4th decade of our life. If no timely interventions are taken, lifestyle modifications are not done, these conditions can debilitate very severely and may lead to permanent disability also.

To conclude, the current review will prove an eye-opener for the professionals and researchers to broaden their research and enlighten the ever-expanding but much-shrouded field of rheumatic diseases. The importance of this paper can be underscored for therapeutic interventions as well.

\section{Abbreviations Used}

AAV: ANCA-associated vasculitis; ACPA: Anti-citrullinated protein/peptide antibodies; ACR: American College of Rheumatology; ANCA: Anti-neutrophil cytoplasmic autoantibody; ANKH: Progressive ankylosis homolog; ATP: Adenosine triphosphate; BCP: Basic calcium phosphate; BMD: Bone mineral density; c-ANCA: Cytoplasmic- ANCA; CPPD: Calcium pyrophosphate dihydrate; CR: Conventional radiography; CRP: C-reactive protein; CT: Computed tomography; DECT: Dual-energy CT; DXA: Dual-energy X-ray absorptiometry; EGPA: Eosinophilic granulomatosis with polyangiitis; ENPP1: Ectonucleotide pyrophosphatase phosphodiesterase 1; EORA: Elderly-onset rheumatoid arthritis; ESR: Erythrocyte sedimentation rate; EUL: Elevation of the upper limbs; EULAR: European League Against Rheumatism; GCs: Glucocorticoids; GCA: Giant cell arteritis; GPA: Granulomatosis with polyangiitis; HLA: Human leukocyte antigen; IL: Interleukin; iPP: Inorganic pyrophosphate; MCP: Metacarpophalangeal; MMPs: Matrix metalloproteinases; MPA: Microscopic polyangiitis; MPO: Myeloperoxidase; MRI: Magnetic resonance imaging; MSS: Milwaukee shoulder syndrome; MSU: Monosodium urate; MTX: Methotrexate; NICE: National Institute for Health and Care Excellence; NIH: National Institute of Health; NSAIDs: Non-steroidal anti-inflammatory drugs; OA: Osteoarthritis; OP: Osteoporosis; p-ANCA: Perinuclear ANCA; PET: Positron emission tomography; PMR: Polymyalgia rheumatica; PR3: Proteinase-3; PTH: Parathyroid hormone; RA: Rheumatoid arthritis; RANKL: Receptor activator of nuclear factor KB ligand; RF: Rheumatoid factor; ROL: Renal overload; RS3PE: Remitting seronegative symmetrical synovitis with pitting edema; RUE: Renal underexcretion; SA: Septic arthritis; SERMs: Selective estrogen-receptor modulators; SF: Synovial fluid; SLE: Systemic lupus erythematosus; SS: Sjögren's syndrome; TAB: Temporal artery biopsy; TAK1: TGF $\beta$-activated kinase 1; TGF $\beta$ : Transforming growth factor $\beta$; TNF: Tumor necrosis factor; ULT: Urate-lowering therapy; US: Ultrasonography; UUE: Urinary urate excretion; VAS: Visual analog scale; WHO: World Health Organization; YLD: Years lived with disability; YORA: Youngonset rheumatoid arthritis. 


\section{Author Contributions}

C. Castellani, E. Molteni, S. Colafrancesco collected the references and wrote the paper. F. Conti and R. Priori critically revised the paper. R. Scrivo analyzed the references and critically revised the paper.

\section{Competing Interests}

The authors have declared that no competing interests exist.

\section{References}

1. EULAR. Ten facts about Rheumatic and Musculoskeletal Diseases (RMDs)[Internet]. Kilchberg: The European League Against Rheumatism; Available from: https://www.eular.org/myUploadData/files/EULAR_Ten_facts_about_RMDs.pdf.

2. Briggs AM, Cross MJ, Hoy DG, Sanchez-Riera L, Blyth FM, Woolf AD, et al. Musculoskeletal health conditions represent a global threat to healthy aging: A report for the 2015 World Health Organisation world report on ageing and health. Gerontologist. 2016; 56: S243-S255.

3. Fried LP, Tangen CM, Walston J, Newman AB, Hirsch C, Gottdiener J, et al. Frailty in older adults: Evidence for a phenotype. J Gerontol A Biol Sci Med Sci. 2001; 56: M146-M157.

4. Morley JE, Vellas B, Van Kan GA, Anker SD, Bauer JM, Bernabei R, et al. Frailty consensus: A call to action. J Am Med Dir Assoc. 2013; 14: 392-397.

5. Kuo CF, Grainge MJ, Mallen C, Zhang W, Doherty M. Comorbidities in patients with gout prior to and following diagnosis: Case-control study. Ann Rheum Dis. 2016; 75: 210-217.

6. Hellmich B, Agueda A, Monti S, Buttgereit F, De Boysson H, Brouwer E, et al. 2018 update of the EULAR recommendations for the management of large vessel vasculitis. Ann Rheum Dis. 2020; 79: 19-30.

7. GBD 2016 Lower Respiratory Infections Collaborators. Global, regional, and national incidence, prevalence, and years lived with disability for 328 diseases and injuries for 195 countries, 1990-2016: A systematic analysis for the global burden of disease study 2016. Lancet. 2017; 390: 1211-1259.

8. González-Gay MA, Matteson EL, Castañeda S. Polymyalgia rheumatica. Lancet. 2017; 390: 1700-1712.

9. Manzo C. Incidence and prevalence of polymyalgia rheumatica (PMR): The importance of the epidemiological context. The Italian Case Med Sci. 2019; 7: 92.

10. Okumura T, Tanno S, Ohhira M, Nozu T. The rate of polymyalgia rheumatica (PMR) and remitting seronegative symmetrical synovitis with pitting edema (RS3PE) syndrome in a clinic where primary care physicians are working in Japan. Rheumatol Int. 2012; 32: 1695-1699.

11. Crowson CS, Matteson EL, Myasoedova E, Michet CJ, Ernste FC, Warrington KJ, et al. The lifetime risk of adult-onset rheumatoid arthritis and other inflammatory autoimmune rheumatic diseases. Arthritis Rheum. 2011; 63: 633-639.

12. González-Gay MA, Hajeer AH, Dababneh A, Garcia-Porrua C, Mattey DL, Amoli MM, et al. IL-6 promoter polymorphism at position-174 modulates the phenotypic expression of polymyalgia rheumatica in biopsy-proven giant cell arteritis. Clin Exp Rheumatol. 2002; 20: 179-184. 
13. González-Gay MA, Amoli MM, Garcia-Porrua C, Ollier WE. Genetic markers of disease susceptibility and severity in giant cell arteritis and polymyalgia rheumatica. Semin Arthritis Rheum. 2003; 33: 38-48.

14. Gerardi MC, Rutigliano IM, Scrivo R, Priori R, Riccieri V, Valesini G. "In sickness and in health": The peculiar occurrence of polymyalgia rheumatica in married cohabiting couples--A case series and review of the literature. Clin Rheumatol. 2016; 35: 1111-1115.

15. Straub RH, Glück T, Cutolo M, Georgi J, Helmke K, Schölmerich J, et al. The adrenal steroid status in relation to inflammatory cytokines (interleukin-6 and tumour necrosis factor) in polymyalgia rheumatica. Rheumatology. 2000; 39: 624-631.

16. Straub RH, Cutolo M. Further evidence for insufficient hypothalamic-pituitary-glandular axes in polymyalgia rheumatica. J Rheumatol. 2006; 33: 1219-1223.

17. González-Gay MA. Giant cell arteritis and polymyalgia rheumatica: Two different but often overlapping conditions. Semin Arthritis Rheum. 2004; 33: 289-293.

18. Scrivo R, Silvestri V, Ciciarello F, Sessa P, Rutigliano I, Sestili C, et al. An exploratory crosssectional study of subclinical vascular damage in patients with polymyalgia rheumatica. Sci Rep. 2020; 10: 1-8.

19. Scrivo R, Gerardi MC, Rutigliano I, Sessa P, Mipatrini D, Stricchiola GM, et al. Polymyalgia rheumatica and diverticular disease: Just two distinct age-related disorders or more? Results from a case-control study. Clin Rheumatol. 2018; 37: 2573-2577.

20. Dasgupta B, Cimmino MA, Kremers HM, Schmidt WA, Schirmer M, Salvarani C, et al. 2012 Provisional classification criteria for polymyalgia rheumatica: A European League Against Rheumatism/American College of Rheumatology collaborative initiative. Arthritis Rheum. 2012; 64: 943-954.

21. Leeb BF, Bird HA. A disease activity score for polymyalgia rheumatica. Ann Rheum Dis. 2004; 63: 1279-1283.

22. Loricera J, Blanco R, Hernández JL, Carril JM, Martínez-Rodríguez I, Canga A, et al. Noninfectious aortitis: A report of 32 cases from a single tertiary center in a 4-year period and literature review. Clin Exp Rheumatol. 2015; 33: 19-31.

23. Dejaco C, Singh YP, Perel P, Hutchings A, Camellino D, Mackie S, et al. 2015 Recommendations for the management of polymyalgia rheumatica: A European League Against Rheumatism/American College of Rheumatology collaborative initiative. Ann Rheum Dis. 2015; 74: 1799-1807.

24. Hancock AT, Mallen CD, Muller S, Belcher J., Roddy E., Helliwell T, et al. Risk of vascular events in patients with polymyalgia rheumatica. CMAJ. 2014; 186: E495-E501.

25. McCarty DJ, O'Duffy JD, Pearson L, Hunter JB. Remitting seronegative symmetrical synovitis with pitting edema. JAMA. 1985; 254: 2763-2767.

26. Cantini F, Salvarani C, Olivieri I, Barozzi L, Macchioni L, Niccoli L, et al. Remitting seronegative symmetrical synovitis with pitting oedema (RS3PE) syndrome: A prospective follow up and magnetic resonance imaging study. Ann Rheum Dis. 1999; 58: 230-236.

27. Salvarani C, Cantini F, Macchioni P, Olivieri I, Niccoli L, Padula A, et al. Distal musculoskeletal manifestations in polymyalgia rheumatica: A prospective follow-up study. Arthritis Rheum. 1998; 41: 1221-1226.

28. Olivieri I, Padula A, Pierro A, Favaro L, Oranges GS, Ferri S. Late onset undifferentiated seronegative spondylarthropathy. J Rheumatol. 1995; 22: 899-903. 
29. Olivieri I, Salvarani C, Cantini F. Remitting distal extremity swelling with pitting edema: A distinct syndrome or a clinical feature of different inflammatory rheumatic diseases? J Rheumatol. 1997; 24: 249-252.

30. Bhakta BB, Pease CT. Late-onset rheumatoid arthritis: Is pitting oedema of the hands at onset a good prognostic indicator? Br J Rheumatol. 1997; 36: 214-219.

31. Hegazi MO, Saleh F, Al Rashidi A, Yaktien MM. Synovitis with pitting edema as the presenting manifestation of systemic lupus erythematosus. Lupus. 2014; 23: 1069-1072.

32. Olivo D, Mattace R. Concurrence of benign edematous polysynovitis in the elderly (RS3PE syndrome) and endometrial adenocarcinoma. Scand J Rheumatol. 1997; 26: 67-68.

33. Tada $Y$, Sato $H$, Yoshizawa $S$, Kimura $H$, Kitamura $M$, Kusabe $T$, et al. Remitting seronegtive symmetrical synovitis with pitting edema associated with gastric carcinoma. J Rheumatol. 1997; 24: 974-975.

34. Crowson CS, Matteson EL. Contemporary prevalence estimates for giant cell arteritis and polymyalgia rheumatica, 2015. Semin Arthritis Rheum. 2017; 47: 253-256.

35. Gonzalez-Gay MA, Miranda-Filloy JA, Lopez-Diaz MJ, Perez-Alvarez R, Gonzalez-Juanatey C, Sanchez-Andrade A, et al. Giant cell arteritis in northwestern Spain: A 25-year epidemiologic study. Medicine. 2007; 86: 61-68.

36. Gonzalez-Gay MA, Vazquez-Rodriguez TR, Lopez-Diaz MJ, Miranda-Filloy JA, GonzalezJuanatey C, Martin J, et al. Epidemiology of giant cell arteritis and polymyalgia rheumatica. Arthrit Care Res. 2009; 61: 1454-1461.

37. Salvarani C, Cantini F, Hunder GG. Polymyalgia rheumatica and giant-cell arteritis. Lancet. 2008; 372: 234-245.

38. Dejaco C, Brouwer E, Mason JC, Buttgereit F, Matteson EL, Dasgupta B. Giant cell arteritis and polymyalgia rheumatica - current challenges and opportunities. Nat Rev Rheumatol. 2017; 13: 578.

39. González-Gay MÁ, Ortego-Jurado M, Ercole L, Ortego-Centeno N. Giant cell arteritis: Is the clinical spectrum of the disease changing? BMC Geriatr. 2019; 19: 200.

40. Karahaliou M, Vaiopoulos G, Papaspyrou S, Kanakis MA, Revenas K, Sfikakis PP. Colour duplex sonography of temporal arteries before decision for biopsy: A prospective study in 55 patients with suspected giant cell arteritis. Arthritis Res Ther. 2006; 8: R116.

41. Winkler A, True D. Giant cell arteritis: 2018 review. Mo Med. 2018; 115: 468.

42. Narváez J, Bernad B, Roig-Vilaseca D, García-Gómez C, Gómez-Vaquero C, Juanola X, et al. Influence of previous corticosteroid therapy on temporal artery biopsy yield in giant cell arteritis. Semin Arthritis Rheum. 2007; 37: 13-19.

43. Achkar AA, Lie JT, Hunder GG, O'Fallon WM, Gabriel SE. How does previous corticosteroid treatment affect the biopsy findings in giant cell (temporal) arteritis? Ann Intern Med. 1994; 120: 987-992.

44. Ypsilantis E, Courtney ED, Chopra N, Karthikesalingam A, Eltayab M, Katsoulas N, et al. Importance of specimen length during temporal artery biopsy. Brit J Surg. 2011; 98: 15561560.

45. Stone JH, Tuckwell K, Dimonaco S, Klearman M, Aringer M, Blockmans D, et al. Trial of tocilizumab in giant-cell arteritis. New Engl J Med. 2017; 377: 317-328.

46. Muratore F, Kermani TA, Crowson CS, Green AB, Salvarani C, Matteson EL, et al. Large-vessel giant cell arteritis: A cohort study. Rheumatology. 2015; 54: 463-470. 
47. Gonzalez-Gay MA, Piñeiro A, Gomez-Gigirey A, Garcia-Porrua C, Pego-Reigosa R, DierssenSotos $\mathrm{T}$, et al. Influence of traditional risk factors of atherosclerosis in the development of severe ischemic complications in giant cell arteritis. Medicine. 2004; 83: 342-347.

48. Yates M, Watts R. ANCA-associated vasculitis. Clin Med. 2017; 17: 60.

49. Greco A, Marinelli C, Fusconi M, Macri GF, Gallo A, De Virgilio A, et al. Clinic manifestations in granulomatosis with polyangiitis. Int J Immunopath Pharmacol. 2016; 29: 151-159.

50. Raghunathan V, Pelcovits A, Gutman D, Carino G. Cardiogenic shock from coronary vasculitis in granulomatosis with polyangiitis. BMJ Case Rep. 2017; 2017: bcr2017.

51. Furuta S, Iwamoto T, Nakajima $\mathrm{H}$. Update on eosinophilic granulomatosis with polyangiitis. Allergol Int. 2019; 68: 430-436.

52. García-Nava M, Mateos-Toledo H, Guevara-Canseco APG, Infante-González CE, Reyes-Nava DA, Estrada-Castro E. Early interstitial lung disease in microscopic polyangiitis: Case report and literature review. Reumatol Clin. 2018; 14: 106-108.

53. Yates $M$, Watts RA, Bajema IM, Cid MC, Crestani $B$, Hauser $T$, et al. EULAR/ERA-EDTA recommendations for the management of ANCA-associated vasculitis. Ann Rheum Dis. 2016; 75: 1583-1594.

54. Karadag O, Jayne DJ. Polyarteritis nodosa revisited: A review of historical approaches, subphenotypes and a research agenda. Clin Exp Rheumatol. 2018; 36: 135-142.

55. Mulay SR, Anders HJ. Crystallopathies. N Engl J Med. 2016; 374: 2465-2476.

56. Richette P, Bardin T. Gout. Lancet. 2010; 375: 318-328.

57. Dalbeth N, Merriman TR, Stamp LK. Gout. Lancet. 2016; 388: 2039-2052.

58. Neogi T, Jansen TL, Dalbeth N, Fransen J, Schumacher HR, Berendsen D, et al. 2015 Gout classification criteria: An American College of Rheumatology/European League Against Rheumatism collaborative initiative. Ann Rheum Dis. 2015; 74: 1789-1798.

59. Ragab G, Elshahaly M, Bardin T. Gout: An old disease in new perspective - a review. J Adv Res. 2017; 8: 495-511.

60. Nakayama A, Nakaoka H, Yamamoto K, Sakiyama M, Shaukat A, Toyoda Y, et al. Eurogout Consortium. GWAS of clinically defined gout and subtypes identifies multiple susceptibility loci that include urate transporter genes. Ann Rheum Dis. 2017; 76: 869-877.

61. Nielsen SM, Zobbe K, Kristensen LE, Christensen R. Nutritional recommendations for gout: An update from clinical epidemiology. Autoimmun Rev. 2018; 17: 1090-1096.

62. Richette P, Doherty M, Pascual E, Barskova V, Becce F, Castaneda J, et al. 2018 updated European League Against Rheumatism evidence-based recommendations for the diagnosis of gout. Ann Rheum Dis. 2020; 79: 31-38.

63. Richette P, Doherty M, Pascual E, Barskova V, Becce F, Castañeda-Sanabria J, et al. 2016 updated EULAR evidence-based recommendations for the management of gout. Ann Rheum Dis. 2017; 76: 29-42.

64. Hansildaar R, Vedder D, Baniaamam M, Tausche AK, Gerritsen M, Nurmohamed MT. Cardiovascular risk in inflammatory arthritis: Rheumatoid. Lancet Rheumatol. 2020; doi: 10.1016/S2665-9913(20)30221-6.

65. García-Esquinas E, Guallar-Castillón P, Carnicero JA, Buño A, García-García FJ, RodríguezMañas $L$, et al. Serum uric acid concentrations and risk of frailty in older adults. Exp Gerontol. 2016; 82: 160-165. 
66. Abhishek A, Neogi T, Choi H, Doherty M, Rosenthal AK, Terkeltaub R. Review: Unmet needs and the path forward in joint disease associated with calcium pyrophosphate crystal deposition. Arthritis Rheumatol. 2018; 70: 1182-1191.

67. Filippou G, Scirè CA, Adinolfi A, Damjanov NS, Carrara G, Bruyn GAW, et al. Identification of calcium pyrophosphate deposition disease (CPPD) by ultrasound: Reliability of the OMERACT definitions in an extended set of joints - an international multiobserver study by the OMERACT calcium pyrophosphate deposition disease ultrasound subtask force. Ann Rheum Dis. 2018; 77: 1194-1199.

68. Rosenthal AK, Ryan LM. Calcium pyrophosphate deposition disease. N Engl J Med. 2016; 374: 2575-2584.

69. Zhang W, Doherty M, Bardin T, Barskova V, Guerne PA, Jansen TL, et al. European League Against Rheumatism recommendations for calcium pyrophosphate deposition. Part I: Terminology and diagnosis. Ann Rheum Dis. 2011; 70: 563-570.

70. Mitton-Fitzgerald E, Gohr CM, Bettendorf B, Rosenthal AK. The role of ANK in calcium pyrophosphate deposition disease. Curr Rheumatol Rep. 2016; 18: 25.

71. Godfrin-Valnet M, Godfrin G, Godard J, Prati C, Toussirot E, Michel F, et al. Eighteen cases of crowned dens syndrome: Presentation and diagnosis. Neurochirurgie. 2013; 59: 115-120.

72. Zhang W, Doherty M, Pascual E, Barskova V, Guerne PA, Jansen TL, et al. EULAR recommendations for calcium pyrophosphate deposition. Part II: Management. Ann Rheum Dis. 2011; 70: 571-575.

73. Hongsmatip P, Cheng KY, Kim C, Lawrence DA, Rivera R, Smitaman E. Calcium hydroxyapatite deposition disease: Imaging features and presentations mimicking other pathologies. Eur J Radiol. 2019; 120: 108653.

74. Hameed M, Turkiewicz A, Englund M, Jacobsson L, Kapetanovic MC. Prevalence and incidence of non-gout crystal arthropathy in southern Sweden. Arthritis Res Ther. 2019; 21: 291.

75. Doumas C, Vazirani RM, Clifford PD, Owens P. Acute calcific periarthritis of the hand and wrist: A series and review of the literature. Emerg Radiol. 2007; 14: 199-203.

76. McCarthy GM, Dunne A. Calcium crystal deposition diseases - beyond gout. Nat Rev Rheumatol. 2018; 14: 592-602.

77. Stack J, McCarthy GM. Rheumatology 7th ed. London: Elsevier; 2018. p.1632-p.1638.

78. McCarthy GM, Carrera GF, Ryan LM. Acute calcific periarthritis of the finger joints: A syndrome of women. J Rheumatol. 1993; 20: 1077-1080.

79. Nadarajah CV, Weichert I. Milwaukee shoulder syndrome. Case Rep Rheumatol. 2014; 2014 : 458708.

80. Dieppe PA, Doherty M, Macfarlane DG, Hutton CW, Bradfield JW, Watt I. Apatite associated destructive arthritis. Br J Rheumatol. 1984; 23: 84-91.

81. MacMullan P, McMahon G, McCarthy G. Detection of basic calcium phosphate crystals in osteoarthritis. Joint Bone Spine. 2011; 78: 358-363.

82. Becce F, Viry A, Stamp LK, Pascart T, Budzik JF, MARS Collaboration, et al. Winds of change in imaging of calcium crystal deposition diseases. Joint Bone Spine. 2019; 86: 665-668.

83. Ruban TN, Albert L. Wrist involvement of calcium hydroxyapatite deposition disease. J Rheumatol. 2015; 42: 1724-1725.

84. Bijlsma JWJ, Berenbaum F, Lafeber FPJG. Osteoarthritis: An update with relevance for clinical practice. Lancet. 2011; 377: 2115-2126. 
85. Kuettner K, Goldberg VM, eds. Osteoarthritic disorders. Rosemont: American Academy of Orthopaedic Surgeons. 1995: 21-25.

86. Vina ER, Kwoh CK. Epidemiology of osteoarthritis: Literature update. Curr Opin Rheumatol. 2018; 30: 160-167.

87. Litwic A, Edwards MH, Dennison EM, Cooper C. Epidemiology and burden of osteoarthritis. $\mathrm{Br}$ Med Bull. 2013; 105: 185-199.

88. Hawker GA. Osteoarthritis is a serious disease. Clin Exp Rheumatol. 2019; 37: 3-6.

89. Hunter DJ, Schofield D, Callander E. The individual and socioeconomic impact of osteoarthritis. Nat Rev Rheumatol. 2014; 10: 437-441.

90. Reynard LN, Loughlin J. Insights from human genetic studies into the pathways involved in osteoarthritis. Nat Rev Rheumatol. 2013; 9: 573-583.

91. Berenbaum F, Wallace IJ, Lieberman DE, Felson DT. Modern-day environmental factors in the pathogenesis of osteoarthritis. Nat Rev Rheumatol. 2018; 14: 674-681.

92. Scrivo R, Vasile M, Müller-Ladner U, Neumann E, Valesini G. Rheumatic diseases and obesity: Adipocytokines as potential comorbidity biomarkers for cardiovascular diseases. Mediators Inflamm. 2013; 2013: 808125.

93. Driscoll C, Chanalaris A, Knights C, Ismail H, Sacitharan PK, Gentry C, et al. Nociceptive sensitizers are regulated in damaged joint tissues, including articular cartilage, when osteoarthritic mice display pain behavior. Arthritis Rheumatol. 2016; 68: 857-867.

94. Vincent TL. Mechanoflammation in osteoarthritis pathogenesis. Semin Arthritis Rheum. 2019; 49: S36-S38.

95. Mehana ESE, Khafaga AF, El-Blehi SS. The role of matrix metalloproteinases in osteoarthritis pathogenesis: An updated review. Life Sci. 2019; 234: 116786.

96. Wang M, Sampson ER, Jin H, Li J, Ke QH, Im HJ, et al. MMP13 is a critical target gene during the progression of osteoarthritis. Arthritis Res Ther. 2013; 15: R5.

97. Whittle R, Jordan KP, Thomas E, Peat G. Average symptom trajectories following incident radiographic knee osteoarthritis: Data from the Osteoarthritis Initiative. RMD Open. 2016; 2: e000281.

98. Duncan R, Peat G, Thomas E, Hay EM, Croft P. Incidence, progression and sequence of development of radiographic knee osteoarthritis in a symptomatic population. Ann Rheum Dis. 2011; 70: 1944-1948.

99. Lee YC, Nassikas NJ, Clauw DJ. The role of the central nervous system in the generation and maintenance of chronic pain in rheumatoid arthritis, osteoarthritis and fibromyalgia. Arthritis Res Ther. 2011; 13: 211.

100.Sakellariou G, Conaghan PG, Zhang W, Bijlsma JWJ, Boyesen P, D'Agostino MA, et al. EULAR recommendations for the use of imaging in the clinical management of peripheral joint osteoarthritis. Ann Rheum Dis. 2017; 76: 1484-1494.

101.Kloppenburg M, Kroon FP, Blanco FJ, Doherty M, Dziedzic KS, Greibrokk E, et al. 2018 update of the EULAR recommendations for the management of hand osteoarthritis. Ann Rheum Dis. 2019; 78: 16-24.

102.Jordan KM, Arden NK, Doherty M, Bannwarth B, Bijlsma JWJ, Dieppe P, et al. EULAR Recommendations 2003: An evidence based approach to the management of knee osteoarthritis: Report of a task force of the standing committee for international clinical studies including therapeutic trials (ESCISIT). Ann Rheum Dis. 2003; 62: 1145-1155. 
103.Zhang W, Doherty M, Arden N, Bannwarth B, Bijlsma J, Guntheret K-P, et al. EULAR evidence based recommendations for the management of hip osteoarthritis: Report of a task force of the EULAR standing committee for international clinical studies including therapeutics (ESCISIT). Ann Rheum Dis. 2005; 64: 669-681.

104.Zhang W, Nuki G, Moskowitz RW, Abramson S, Altman RD, Arden NK, et al. OARSI recommendations for the management of hip and knee osteoarthritis: Part III. Changes in evidence following systematic cumulative update of research published through January 2009. Osteoarthritis Cartilage. 2010; 18: 476-499.

105. NICE. Osteoarthritis: Care and management in adults. Clinical Guideline CG177. London: National Institute for Health and Clinical Excellence; 2014. Available from: http://www.nice.org.uk/guidance/cg177.

106. Fernandes L, Hagen KB, Bijlsma JW, Andreassen O, Christensen P, Conaghan PG, et al. EULAR recommendations for the non-pharmacological core management of hip and knee osteoarthritis. Ann Rheum Dis. 2013; 72: 1125-1135.

107. Castell MV, van der Pas S, Otero A, Siviero P, Dannison E, Denkinger M, et al. Osteoarthritis and frailty in elderly individuals across six European countries: Results from the European Project on OSteoArthritis (EPOSA). BMC Musculoskelet Disord. 2015; 16: 359.

108. World Health Organization. Assessment of fracture risk and its application to screening for postmenopausal osteoporosis. Geneva: World Health Organization Technical Report Series; 1994. p.843.

109. NIH Consensus Development Panel on Osteoporosis Prevention, Diagnosis, and Therapy. Osteoporosis prevention, diagnosis, and therapy. JAMA. 2001; 285: 785-795.

110.Kanis JA. Assessment of fracture risk and its application to screening for postmenopausal osteoporosis: Synopsis of a WHO report. Osteoporos Int. 1994; 4: 368-381.

111. Baccaro LF, Conde DM, Costa-Paiva L, Pinto-Neto AM. The epidemiology and management of postmenopausal osteoporosis: A viewpoint from Brazil. Clin Interv Aging. 2015; 10: 583-591.

112. Bliuc D, Nguyen ND, Milch VE, Nguyen TV, Eisman JA, Center JR. Mortality risk associated with low-trauma osteoporotic fracture and subsequent fracture in men and women. JAMA. 2009; 301: 513-521.

113.Van Staa TP, Denni son EM, Leufkens HG, Cooper C. Epidemiology of fractures in England and Wales. Bone. 2001; 29: 517-522.

114. Felsenberg D, Silman A., Lunt M, Armbrecht G, Ismail AA, Finn J, et al. Incidence of vertebral fracture in Europe: Results from the European prospective osteoporosis study (EPOS). J Bone Miner Res. 2002; 17: 716-724.

115.Vandenbroucke A, Luyten FP, Flamaing J, Gielen E. Pharmacological treatment of osteoporosis in the oldest old. Clin Interv Aging. 2017; 12: 1065-1077.

116. Rosen CJ. The epidemiology and pathogenesis of osteoporosis. Endotext [Internet]. South Dartmouth, MA: MDText.com, Inc.; 2020.

117.Gillespie LD, Robertson MC, Gillespie WJ, Sherrington C, Gates S, Clemson LM, et al. Interventions for preventing falls in older people living in the community. Cochrane Database Syst Rev. 2012; CD007146.

118. Yang DH, Yang MY. The role of macrophage in the pathogenesis of osteoporosis. Int J Mol Sci. 2019; 20: 2093. 
119.Cannarella R, Barbagallo F, Condorelli RA, Aversa A, La Vignera S, Calogero AE. Osteoporosis from an endocrine perspective: The role of hormonal changes in the elderly. J Clin Med. 2019; 8: 1564.

120.Silverman SL, Christiansen C, Genant HK, Vukicevic S, Zanchetta JR, de Villiers TJ, et al. Efficacy of bazedoxifene in reducing new vertebral fracture risk in postmenopausal women with osteoporosis: Results from a 3-year, randomized, placebo-, and active controlled clinical trial. J Bone Miner Res. 2008; 23: 1923-1934.

121.Cummings SR, Ensrud K, Delmas PD, LaCroix AZ, Vukicevic S, Reid DM, et al. Lasofoxifene in postmenopausal women with osteoporosis. N Engl J Med. 2010; 362: 686-696.

122. Kearns AE, Khosla S, Kostenuik PJ. Receptor activator of nuclear factor kappaB ligand and osteoprotegerin regulation of bone remodeling in health and disease. Endocr Rev. 2008; 29: 155-192.

123. Hodsman AB, Bauer DC, Dempster DW, Dian L, Hanley DA, Harris ST, et al. Parathyroid hormone and teriparatide for the treatment of osteoporosis: $A$ review of the evidence and suggested guidelines for its use. Endocr Rev. 2005; 26: 688-703.

124.Adami S, Giannini S, Bianchi G, Sinigaglia L, Di Munno O, Fiore CE, et al. Vitamin D status and response to treatment in postmenopausal osteoporosis. Osteoporos Int. 2009; 20: 239-244.

125. Bartosch P, McGuigan FE, Akesson KE. Progression of frailty and prevalence of osteoporosis in a community cohort of older women-a 10-year longitudinal study. Osteoporos Int. 2019; 30: 701.

126. Ensrud KE, Ewing SK, Taylor BC, Fink HA, Stone KL, Cauley J, et al. Study of osteoporotic fractures research group. Frailty and risk of falls, fracture, and mortality in older women: The study of osteoporotic fractures. J Gerontol A Biol Sci Med Sci. 2007; 62: 744-751.

127.García-Arias M, Balsa A, Mola EM. Septic arthritis. Best Pract Res Clin Rheumatol. 2011; 25 : 407-421.

128. Mathews CJ, Weston VC, Jones A, Field M, Coakley G. Bacterial septic arthritis in adults. Lancet. 2010; 375: 846-855.

129.Geirsson ÁJ, Statkevicius S, Víkingsson A. Septic arthritis in Iceland 1990-2002: Increasing incidence due to iatrogenic infections. Ann Rheum Dis. 2008; 67: 638-643.

130.Kaandorp CJ, Dinant HJ, van de Laar MA, Moens HJ, Prins AP, Dijkmans BA. Incidence and sources of native and prosthetic joint infection: A community based prospective survey. Ann Rheum Dis. 1997; 56: 470-475.

131.Gavet F, Tournadre A, Soubrier M, Ristori JM, Dubost JJ. Septic arthritis in patients aged 80 and older: A comparison with younger adults. J Am Geriatr Soc. 2005; 53: 1210-1213.

132. Morgan DS, Fisher D, Merianos A, Currie BJ. An 18-year clinical review of septic arthritis from tropical Australia. Epidemiol Infect. 1996; 117: 423-428.

133. Nair R, Schweizer ML, Singh N. Septic arthritis and prosthetic joint infections in older adults. Infect Dis Clin North Am. 2017; 31: 715-729.

134.Wu CJ, Huang CC, Weng SF, Chen PJ, Hsu CC, Wang JJ, et al. Septic arthritis significantly increased the long-term mortality in geriatric patients. BMC Geriatr. 2017; 17: 178.

135. Malnick SD, Beergabel M, Lurie Y. Septic arthritis. Lancet. 1998; 351: 1060.

136.Shemesh S, Heller S, Salai M, Velkes S. Septic arthritis of the knee following intraarticular injections in elderly patients: Report of six patients. Isr Med Assoc J. 2011; 13: 757-760. 
137. Al-Nammari SS, Bobak P, Venkatesh R. Methicillin resistant Staphylococcus aureus versus methicillin sensitive Staphylococcus aureus adult haematogenous septic arthritis. Arch Orthop Trauma Surg. 2007; 127: 537-542.

138. Frazee BW, Fee C, Lambert L. How common is MRSA in adult septic arthritis? Ann Emerg Med. 2009; 54: 695-700.

139. García-De La Torre I, Nava-Zavala A. Gonococcal and nongonococcal arthritis. Rheum Dis Clin North Am. 2009; 35: 63-73.

140.Carpenter CR, Schuur JD, Everett WW, Pines JM. Evidence-based diagnostics: Adult septic arthritis. Acad Emerg Med. 2011; 18: 781-796.

141.Learch TJ, Farooki S. Magnetic resonance imaging of septic arthritis. Clin Imaging. 2000; 24: 236-242.

142. Mathews CJ, Coakley G. Septic arthritis: Current diagnostic and therapeutic algorithm. Curr Opin Rheumatol. 2008; 20: 457-462.

143.Shirtliff ME, Mader JT. Acute septic arthritis. Clin Microbiol Rev. 2002;15: 527-544.

144.Smolen JS, Aletaha D, McInnes IB. Rheumatoid arthritis. Lancet. 2016; 388: 2023-2038.

145.van Schaardenburg D, Breedveld FC. Elderly-onset rheumatoid arthritis. Semin Arthritis Rheum. 1994; 23: 367-378.

146. Carbonell J, Cobo T, Balsa A, Descalzo MA, Carmona L. The incidence of rheumatoid arthritis in Spain: Results from a nationwide primary care registry. Rheumatology. 2008; 47: 1088-1092.

147. Rasch EK, Hirsch R, Paulose-Ram R, Hochberg MC. Prevalence of rheumatoid arthritis in persons 60 years of age and older in the United States: Effect of different methods of case classification. Arthritis Rheum. 2003; 48: 917-926.

148. Targońska-Stępniak B. Rheumatoid arthritis in elderly people. Wiad Lek. 2019; 72: 1676-1682.

149.Lopez-Hoyos M, Ruiz de Alegria C, Blanco R, Crespo J, Peña M, Rodriguez-Valverde V, et al. Clinical utility of anti-CCP antibodies in the differential diagnosis of elderly-onset rheumatoid arthritis and polymyalgia rheumatica. Rheumatology. 2004; 43: 655-657.

150.Spinel-Bejarano N, Quintana G, Heredia R, Yunis JJ, Caminos JE, Garcés MF, et al. Comparative study of elderly-onset rheumatoid arthritis and young-onset rheumatoid arthritis in a Colombian population: Clinical, laboratory and HLA-DRB1 findings. Clin Exp Rheumatol. 2013; 31: 40-46.

151.Bajocchi G, La Corte R, Locaputo A, Govoni M, Trotta F. Elderly onset rheumatoid arthritis: Clinical aspects. Clin Exp Rheumatol. 2000; 18: S49-50.

152.Gregersen PK, Silver J, Winchester RJ. The shared epitope hypothesis: An approach to understanding the molecular genetics of susceptibility to rheumatoid arthritis. Arthritis Rheum. 1987; 30: 1205-1213.

153. Viatte S, Plant D, Han B, Fu B, Yarwood A, Thomson W, et al. Association of HLA-DRB1 haplotypes with rheumatoid arthritis severity, mortality, and treatment response. JAMA. 2015; 313: 1645-1656.

154.Kim EJ, Lee J, Ryu YS, Kim JM, Jeong YG, Kwok SK, et al. Shared epitope and radiologic progression are less prominent in elderly onset RA than young onset RA. Rheumatol Int. 2013; 33: 2135-2140.

155. Oka S, Furukawa H, Shimada K, Hashimoto A, Komiya A, Tsunoda S, et al. Association of HLADRB1 genotype with younger age onset and elder age onset rheumatoid arthritis in Japanese populations. Medicine. 2019; 98: e18218. 
156. Chen DY, Hsieh TY, Chen YM, Hsieh CW, Lan JL, Lin FJ. Proinflammatory cytokine profiles of patients with elderly-onset rheumatoid arthritis: A comparison with younger-onset disease. Gerontology. 2009; 55: 250-258.

157.Radner H, Smolen JS, Aletaha D. Comorbidity affects all domains of physical function and quality of life in patients with rheumatoid arthritis. Rheumatology. 2010; 50: 381-388.

158.Smolen JS, Landewé RBM, Bijlsma JWJ, Burmester GR, Dougados M, Kerschbaumer A, et al. EULAR recommendations for the management of rheumatoid arthritis with synthetic and biological disease-modifying antirheumatic drugs: 2019 update. Ann Rheum Dis. 2020; 79: 685-699.

159.Soubrier M, Mathieu S, Payet S, Dubost JJ, Ristori JM. Elderly-onset rheumatoid arthritis. Joint Bone Spine. 2010; 77: 290-296.

160.Soubrier M, Tatar Z, Couderc M, Mathieu S, Dubost JJ. Rheumatoid arthritis in the elderly in the era of tight control. Drugs Aging. 2013; 30: 863-869.

161.Salaffi F, Di Carlo M, Farah S, Di Donato E, Carotti M. Prevalence of frailty and its associated factors in patients with rheumatoid arthritis: A cross-sectional analysis. Clin Rheumatol. 2019; 38: 1823-1830.

162. Barone F, Colafrancesco S. Sjögren's syndrome: From pathogenesis to novel therapeutic targets. Clin Exp Rheumatol. 2016; 34: 58-62.

163. Koszarny A, Górak A, Majdan M. Late-onset Sjögren's syndrome. Wiad Lek. 2019; 72: 16871690.

164.Al-Hashimi I. Xerostomia secondary to Sjögren's syndrome in the elderly: Recognition and management. Drugs Aging. 2005; 22: 887-899.

165. 165. Qin B, Wang J, Yang Z, Yang M, Ma N, Huang F, et al. Epidemiology of primary Sjögren's syndrome: a systematic review and meta-analysis. Ann Rheum Dis. 2015; 74: 1983-1989.

166.Schein OD, Hochberg MC, Muñoz B, Tielsch JM, Bandeen-Roche K, Provost T, et al. Dry eye and dry mouth in the elderly: A population-based assessment. Arch Intern Med. 1999; 159: 1359-1363.

167.Pennec YL, Leroy JP, Jouquan J, Lelong A, Katsikis P, Youinou P. Comparison of labial and sublingual salivary gland biopsies in the diagnosis of Sjogren's syndrome. Ann Rheum Dis. 1990; 49: 37-39.

168. Fisher BA, Jonsson R, Daniels T, Bombardieri M, Brown RM, Morgan P, et al. Standardisation of labial salivary gland histopathology in clinical trials in primary Sjögren's syndrome. Ann Rheum Dis. 2017; 76: 1161-1168.

169. Greenspan JS, Daniels TE, Talal N, Sylvester RA. The histopathology of Sjogren's syndrome in labial salivary gland biopsies. Oral Surg Oral Med Oral Pathol. 1974; 37: 217-229.

170. Colafrancesco S, Priori R, Smith CG, Minniti A, lannizzotto V, Pipi E, et al. CXCL13 as biomarker for histological involvement in Sjögren's syndrome. Rheumatology. 2020; 59: 165-170.

171. Hochberg MC, Tielsch J, Munoz B, Bandeen-Roche K, West SK, Schein OD. Prevalence of symptoms of dry mouth and their relationship to saliva production in community dwelling elderly: The SEE project. Salisbury Eye Evaluation. J Rheumatol. 1998; 25: 486-491.

172. Drosos AA, Andonopoulos AP, Costopoulos JS, Papadimitriou CS, Moutsopoulos HM. Prevalence of primary Sjogren's syndrome in an elderly population. $\mathrm{Br}$ J Rheumatol. 1988; 27: 123-127. 
173. Vitali C, Bombardieri S, Jonsson R, Moutsopoulos HM, Alexander EL, Carsons SE, et al. Classification criteria for Sjogren's syndrome: A revised version of the European criteria proposed by the American-European Consensus Group. Ann Rheum Dis. 2002; 61: 554-558.

174.Tishler M, Yaron I, Shirazi I, Yaron M. Clinical and immunological characteristics of elderly onset Sjogren's syndrome: A comparison with younger-onset disease. J Rheumatol. 2001; 28: 795-797.

175.García-Carrasco M, Cervera R, Rosas J, Ramos-Casals M, Morlà RM, Siso A, et al. Primary Sjogren's syndrome in the elderly: Clinical and immunological characteristics. Lupus. 1999; 8: 20-23.

176. Ramos-Casals M, Cervera R, Font J, García-Carrasco M, Espinosa G, Reino S, et al. Young onset of primary Sjögren's syndrome: Clinical and immunological characteristics. Lupus. 1998; 7: 202-206.

177.Ramos-Casals M, Brito-Zerón P, Bombardieri S, Bootsma H, De Vita S, Dörner T, et al. EULAR recommendations for the management of Sjögren's syndrome with topical and systemic therapies. Ann Rheum Dis. 2020; 79: 3-18.

178.Ng KP, Isenberg DA. Sjögren's syndrome: Ciagnosis and therapeutic challenges in the elderly. Drugs Aging. 2008; 25: 19-33.

179. Moerman RV, Bootsma H, Kroese FG, Vissink A. Sjögren's syndrome in older patients: Aetiology, diagnosis and management. Drugs Aging. 2013; 30: 137-53

180. Vaudo G, Bartoloni Bocci EB, Shoenfeld Y, Schillaci G, Wu R, Del Papa N, et al. Precocious intima-media thickening in patients with primary Sjögren's syndrome. Arthritis Rheum. 2005; 52: 3890-3897.

181.Bartoloni E, Alunno A, Cafaro G, Valentini V, Bistoni O, Bonifacio AF, et al. Subclinical atherosclerosis in primary Sjögren's syndrome: Does inflammation matter? Front Immunol. 2019; 10: 817.

182. Lalani S, Pope J, de Leon F, Peschen C. Clinical features and prognosis of late-onset systemic lupus erythematosus: Results from the 1000 faces of lupus study. J Rheumatol. 2010; 37: 3844.

183.Padovan M, Govoni M, Castellino G, Rizzo N, Fotinidi M, Trotta F. Late onset systemic lupus erythematosus: No substantial differences using different cut-off ages. Rheumatol Int. 2007; 27: 735-741.

184. Arnaud L, Mathian A, Boddaert J, Amoura Z. Late-onset systemic lupus erythematosus: Epidemiology, diagnosis and treatment. Drugs Aging. 2012; 29: 181-189.

185.Sassi RH, Hendler JV, Piccoli GF, Gasparin AA, da Silva Chakr RM, Brenol JC, et al. Age of onset influences on clinical and laboratory profile of patients with systemic lupus erythematosus. Clin Rheumatol. 2017; 36: 89-95.

186.Tomic-Lucic A, Petrovic R, Radak-Perovic M, Milovanovic D, Milovanovic J, Zivanovic S, et al. Late-onset systemic lupus erythematosus: Clinical features, course, and prognosis. Clin Rheumatol. 2013; 32: 1053-1058.

187. Rovenský J, Tuchyňová A. Systemic lupus erythematosus in the elderly. Autoimm Rev. 2008; 7 : 235-239.

188. Sohn IW, Joo YB, Won S, Bae SC. Late-onset systemic lupus erythematosus: Is it "mild lupus"? Lupus. 2018; 27: 235-242. 
189. Aljohani R, Gladman DD, Su J, Urowitz MB. Disease evolution in late-onset and early-onset systemic lupus erythematosus. Lupus. 2017; 26: 1190-1196.

190. Medhat BM, Behiry ME, Sobhy N, Farag Y, Marzouk H, Mostafa N, et al. Late-onset systemic lupus erythematosus: Characteristics and outcome in comparison to juvenile- and adult-onset patients-a multicenter retrospective cohort. Clin Rheumatol. 2020; 39: 435-442.

191. Feng X, Zou Y, Pan W, Wang X, Wu M, Zhang M, et al. Associations of clinical features and prognosis with age at disease onset in patients with systemic lupus erythematosus. Lupus. 2014; 23: 327-334.

192.Peñaranda-Parada E, Quintana G, Yunis JJ, Mantilla R, Rojas W, Panqueva U, et al. Clinical, serologic, and immunogenetic characterization (HLA-DRB1) of late-onset lupus erythematosus in a Colombian population. Lupus. 2015; 24: 1293-1299.

193. Graham RR, Ortmann W, Rodine P, Espe K, Langefeld C, Lange E, et al. Specific combinations of HLA-DR2 and DR3 class II haplotypes contribute graded risk for disease susceptibility and autoantibodies in human SLE. Eur J Hum Genet. 2007; 15: 823-830.

194.Bertoli AM, Alarcón GS, Calvo-Alén, J, Fernández M, Vilá LM, Reveille JD. Systemic lupus erythematosus in a multiethnic US cohort: Clinical features, course, and outcome in patients with late-onset disease. Arthritis Rheum. 2006; 54: 1580-1587.

195. Katz PP, Andrews J, Yazdany J, Schmajuk G, Trupin L, Yelin E. Is frailty a relevant concept in SLE? Lupus Sci Med. 2017; 4: e000186.

196. Barnett K, Mercer SW, Norbury M, Watt G, Wyke S, Guthrie B. Epidemiology of multimorbidity and implications for health care, research, and medical education: A cross-sectional study. Lancet. 2012; 380: 37-43.

197.Duffield SJ, Ellis BM, Goodson N, Walker-Bone K, Conaghan PG, Margham T, et al. The contribution of musculoskeletal disorders in multimorbidity: Implications for practice and policy. Best Pract Res Clin Rheumatol. 2017; 31: 129-144.

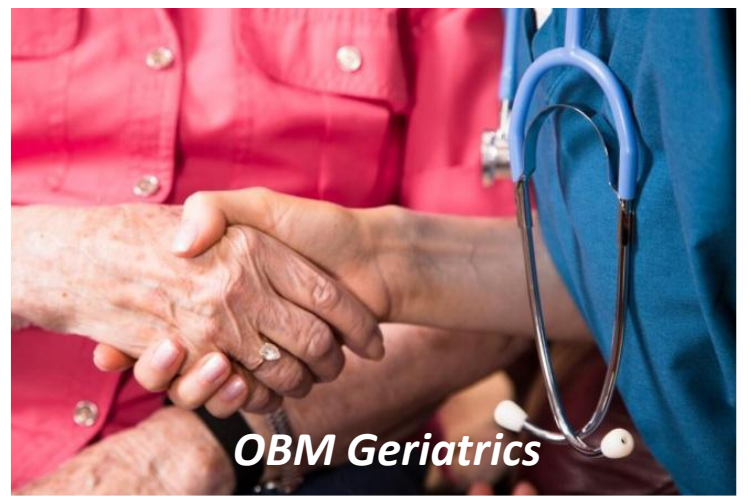

Enjoy OBM Geriatrics by:

1. Submitting a manuscript

2. Joining in volunteer reviewer bank

3. Joining Editorial Board

4. Guest editing a special issue

For more details, please visit: http://www.lidsen.com/journals/geriatrics 